\title{
ESTUDO SOBRE O LETRAMENTO E A METODOLOGIA UTILIZADA PELOS PROFESSORES EM INDIVÍDUOS COM SURDEZ
}

Érica Farias Silva, Tamiris Santana da Silva, Danielle Aparecida do Nascimento dos Santos

Universidade do Oeste Paulista - UNOESTE, Curso de Fonoaudiologia, Presidente Prudente, SP. E-mail: ericafariassilva@hotmail.com

\section{RESUMO}

O estudo destaca a importância do letramento e a metodologia utilizada pelos professores em indivíduos com surdez. O letramento é o individuo que assume saber ler e escrever, este fenômeno é uma atividade da tecnologia da escrita, a qual objetiva-se ler e escrever para realizar objetivos diversos. As dificuldades que os surdos apresentam frente à prática da leitura e da escrita, não esta relacionada com o fato de eles não ouvirem e não dominarem a linguagem oral, mas sim as condições que o meio e o grupo social the propiciam. O presente estudo também irá investigar o nível de letramento em indivíduos com surdez, bem como as práticas de leitura e escrita utilizadas pelos docentes. Para isso a pesquisa será realizada com 15 indivíduos com surdez de ambos os sexos e com faixa etária de 05 a 12 anos, e com 10 professores da mesma instituição que os discentes. Será aplicado um questionário para coletar dados, que irá conter questões abertas e fechadas, para coletar por escrito informações sobre as práticas de leitura e de escrita vivenciadas diariamente pelos sujeitos da pesquisa. E com os professores serão utilizados questionários com enfoque na educação escolar do aluno surdo no contexto da inclusão e seu processo de leitura e escrita.

Palavras-chave: Letramento, Pessoas Surda, Metodologia de Ensino.

\section{STUDY ON LETTERING AND METHODOLOGY USED BY TEACHERS IN INDIVIDUALS WITH DEAF}

\begin{abstract}
The study highlights the importance of literacy and the methodology used by teachers in deaf individuals. Literacy is the individual who assumes to know how to read and write, this phenomenon is an activity of writing technology, which aims to read and write to achieve various objectives. The difficulties that the deaf present to the practice of reading and writing are not related to the fact that they do not listen and do not master oral language, but rather the conditions that the medium and the social group provide. The present study will also investigate the level of literacy in deaf individuals, as well as the reading and writing practices used by teachers. For that, the research will be carried out with 15 individuals with deafness of both sexes and with age group of 05 to 12 years, and with 10 professors of the same institution that the students. A questionnaire will be applied to collect data, which will contain open and closed questions, to collect in writing information about the reading and writing practices experienced daily by the research subjects. And with the teachers will be used questionnaires with focus on the school education of the deaf student in the context of inclusion and their reading and writing process.
\end{abstract}

Keyword: Literacy, Deaf People, Teaching Methodology. 


\section{INTRODUÇÃO}

De acordo com Soares (2004), letramento é o estado que assume aquele que sabe ler e escrever, para ela o fenômeno do letramento tem uma forte relação com o alfabetismo, mas não se confunde com esse processo, porém a alfabetização é o processo pelo qual se adquire o domínio de um código e das técnicas para utilizá-lo no momento em que lemos e escrevemos. Letramento é, portanto, a atividade efetiva da tecnologia da escrita, a qual envolve a possibilidade de ler e escrever para cumprir objetivos diversos: informar, interagir com o outro, fazer uma declaração, contar uma história, ampliar conhecimentos, orientar-se, divertir, entre outros.

É por meio do contexto familiar que a criança tem seus primeiros contatos com a linguagem escrita, estabelece seus primeiros significados. Se desde cedo uma criança convive com materiais de leitura, tais como: livros, jornais e revistas, se ouve histórias e observa as pessoas lendo e escrevendo e manipula lápis, borracha, papel, ao ingressar na escola achará tudo muito natural e lógico, já que será uma continuidade daquilo que já vivenciava em casa (CAGLIARI, 1995). De acordo com Guarinello (2007), o acesso a diferentes materiais de leitura em casa, facilita a construção de hipóteses sobre a escrita e a percepção das diferenças entre esta e a fala.

Segundo Gesueli (1998), as dificuldades apresentadas pelos surdos frente às práticas de leitura e escritas não estão relacionadas ao fato de não ouvirem ou de não dominarem a linguagem oral, mas às condições que lhe são propiciadas pelo meio e pelo grupo social. Por isso é importante considerar que, para além dos aspectos relacionados à surdez propriamente dita, a interação familiar é um fator que deve ser ponderado em relação à constituição da leitura e escrita por estes sujeitos.

Atualmente, um número significativo de surdos vem sendo classificado equivocadamente como iletrado pelo fato de fazer uso da escrita sem ter conhecimento da realidade oral da Língua Portuguesa, nem tampouco da língua de sinais. Contudo, é preciso considerar que esse desconhecimento não se deve a questões individuais, pois, no Brasil, a grande maioria dos surdos adultos não domina a Língua Portuguesa.

Além disso, há uma considerável parcela que não teve acesso à língua de sinais, quer seja por motivo de isolamento social, quer seja pelo fato de a família optar por uma escola que não utilize essa língua, o que causa, além de defasagens escolares, dificuldade e/ou impedimento quanto à inserção dessas pessoas no mercado de trabalho (GUARINELLO, 2004). Cabe esclarecer que, ainda hoje no Brasil, são poucas as escolas que oferecem uma proposta bilíngüe, na qual a língua de sinais é a principal língua utilizada na escola, a maioria das escolas brasileiras ainda utiliza somente a Língua Portuguesa.

A educação bilíngue é essencial para instrumentalizar o surdo para torna-se um sujeito letrado, no entanto, essa perspectiva ainda encontra-se envolta em muitas dúvidas e questionamentos por parte dos professores, que por um lado não são proficientes na primeira língua do surdo, pois não tiveram acesso à formação específica para tal.

O surdo precisa desenvolver uma língua efetiva, e, para que isso ocorra, é necessário que as experiências escolares oferecidas a ele privilegiem não apenas a língua de sinais, mas também os aspectos discursivos da escrita, já que esses são fundamentais para que qualquer sujeito, surdo ou ouvinte, se constitua como falante, leitor e escritor, realizando um trabalho que proporcione a reflexão sobre o uso da linguagem oral, escrita e da língua de sinais. Levando em consideração essa realidade e também as dificuldades que os sujeitos surdos apresentam com a linguagem escrita, o artigo versa sobre parte da pesquisa de iniciação científica desenvolvida no âmbito do curso de Fonoaudiologia, que visa apresentar aspectos que caracterizam as condições de letramento em indivíduos com surdez mediante a perspectiva metodológica dos docentes. 


\section{METODOLOGIA}

Contextualização teórica da pesquisa, realizada mediante análise bibliográfica. Foram analisados artigos científicos publicados na área, nas bases de dados Scielo e Google Acadêmico, com recorte temporal de produções publicadas nos últimos 5 anos.

\section{RESULTADOS E DISCUSSÃO}

Segundo Padden (1990), enquanto a criança ouvinte pode usar os conhecimentos que já possui da linguagem oral na constituição da linguagem escrita, fazendo conexões e apoiada em uma língua, a criança surda precisa explorar os conhecimentos da língua portuguesa juntamente com o aprendizado da escrita. Neste sentido, como refere Gesueli (1998), do ponto de vista de uma proposta bilíngüe, a aquisição da língua portuguesa para o surdo é uma tarefa altamente complexa.

De acordo com as pesquisas de Rosa (1998) e Fernandes (1998) apontam e evidenciam as dificuldades dos surdos com a linguagem por conta da maneira como os profissionais lidam com o sujeito surdo, a surdez e a linguagem. A língua muitas vezes é ensinada por meio de atividades mecânicas e repetitivas como se fosse um código pronto e acabado.

A criança surda só irá aprender a escrever ou a falar, quando tiver contato com adultos usuários e competentes nesta língua e quando tem a oportunidade de participar de atividades significativas. No caso específico da escrita, o surdo deve partir de experiências com a língua que já domina, a qual em geral é a língua de sinais, para construir e desenvolver a língua escrita (SVARTHOLM, 1999).

Antia, Reed e Kreimeyer (2005) realizaram uma pesquisa a fim de avaliar o vocabulário, a ortografia, as estruturas frasais e a escrita espontânea dos alunos a partir de figuras. Essa pesquisa revelou que, de um modo geral, apenas $17 \%$ dos alunos tiveram um desempenho acima da média, $32 \%$ alcançaram a média e 51\% tiveram um desempenho abaixo da média, destes 5\% não tiveram nenhuma produção que pudesse ser considerada, resultando em $0 \%$. O teste demonstrou que a maior dificuldade dos surdos foi em relação ao vocabulário e à sintaxe. Entretanto, no que diz respeito à produção espontânea, a maior parte dos alunos tiveram um resultado acima da média.

Fernandes (2006) ressalta que a metodologia na educação de surdos é pensada a partir de recursos e estratégias para a alfabetização de ouvintes, tendo a oralidade como pressuposta. Entretanto, esta é uma realidade inadequada para os surdos, considerando que os mesmos não estabelecem relações grafema-fonema, por ser esta uma experiência auditiva, por isso que a alfabetização não deveria ser o foco na educação dos surdos, mas deveriam ser tomadas como ponto de partida as práticas de letramento.

Segundo Guarinello (2007) as atividades de leitura e escrita partem de exercícios mecânicos e descontextualizados, a escrita é vista apenas sob o ponto de vista escolar, não existe a preocupação em tornar este objeto prazeroso ou ao menos funcional no momento em que é apresentado à criança.

Devem ser usados materiais visuais, a fim de promover a aprendizagem da escrita pelos sujeitos surdos, materiais estes que os interessam mais, como imagens, vídeos, dramatizações. Sugerem também que sejam apresentados a eles diversos gêneros textuais, explorando jornais, cartas, receitas, revistas e etc.

Os próprios materiais, o contexto ao qual estará inserida a escrita deverá ser significativo para este sujeito, para que entenda a funcionalidade e o papel da escrita, sendo de grande importância que sejam utilizadas leituras de assuntos os quais o surdo se interesse.

A comunicação e a linguagem são imprescindíveis para a convivência e a formação do indivíduo em sua totalidade, possibilitando assim a interação com o mundo. Para poderem interagir, o 
ser humano aprende várias formas de comunicação e o desenvolvimento e a aquisição da linguagem iniciam-se a partir do nascimento.

A partir do nascimento e da interação com o meio, a comunicação e a linguagem passam a caminhar juntos. Com base nos estudos de VYGOTSKY (1989), o signo passa a constituir a mediação entre o mundo social e os elementos pertencentes a ele.

A aquisição da linguagem por crianças ouvintes e surdas não pode ser inato, como SACKS (2010) apresenta. É preciso uma troca entre os agentes envolvidos. Desta forma, o documento "Educação Infantil: saberes e práticas da inclusão: dificuldades de comunicação e sinalização: surdez", sugere como atividades de comunicação a serem desenvolvidas: saco surpresa, contação de histórias que foram vivenciadas em classe para a família para o desenvolvimento da escrita, da fala e da Língua.

Já as atividades de rotina, centros de jogos dramáticos, centro de jogos e quebra-cabeças, centro de blocos, centro de biblioteca, centro de matemática, centro de ciências, centro de água e areia, centro de som e música, centro de artes, centro de marionetes, centro de educação física e centro de culinária também devem ter como foco, além da comunicação, a interação e a socialização entre os estudantes.

A partir destas atividades, os educandos podem "desenvolver-se cognitivamente não dependendo exclusivamente do domínio de uma língua, mas dominar uma língua garante os melhores recursos para as cadeias neuronais envolvidas no desenvolvimento dos processos cognitivos" (FERNANDES, 2000, p.49).

Desta forma, os estudos de Quadros (1997) verificaram dois estágios de desenvolvimento da linguagem: o primeiro é chamado de pré-linguístico, no qual os sons não são atribuídos de significado, os sons emitidos são nomeados como balbucios, comuns nos primeiros meses de vida, para ouvintes e surdos. O próximo estágio é o linguístico em que a criança já é capaz de produzir suas primeiras palavras, dando início ao desenvolvimento de sua produção linguística. Entretanto o sucesso deste segundo estágio dependerá da exposição da criança ao ambiente no qual ela está inserida. É necessário que a criança tenha contato com pessoas fluentes na língua em que este indivíduo utilizará para se comunicar.

A comunicação, sendo esta oral ou gestual, propiciará às crianças interações com o meio, o que proporcionará diversas abordagens, sejam elas de ordem comportamental, linguística ou interacionista, propiciando às crianças, desde a mais tenra idade o acesso às regras, as crenças e aos valores pertinentes a sua cultura.

A fluência do profissional que está em contato é destacada, para que uma comunicação efetiva entre os sujeitos seja estabelecida, e que, após exploração mais concreta da leitura, ele possa produzir sua escrita, e, com a ajuda desse profissional, aproximá-la da escrita padrão, até que possa fazê-lo de forma autônoma.

Silva (2010) confirma a importância de tais questões, evidenciando que, ao lidarem com as diferenças das duas línguas, os participantes muitas vezes não relacionam o que é dito em Libras com os elementos do português escrito, o que lhes tira oportunidades de compreenderem o funcionamento dessa língua e construírem habilidades de leitura.

No contexto da surdez, assim como no contexto dos ouvintes, ainda contamos com leitores e escritores que apresentam grande dificuldade no processo de interpretação e produção textual de gêneros secundários.

\section{CONCLUSÃO}

A investigação de conclusão de curso tem como objetivo específico fornecer contribuições relevantes para a reflexão sobre o processo de inclusão de pessoas com surdez, e ainda, refletir sobre 
a gestão de documentos e de manuais que nem sempre estão adequados à realidade dos professores.

É inegável reconhecer a relevância de pesquisas sobre educação bilíngue, uma vez que o ato de ler e escrever é importante para a vida, pois, além de ser recurso de comunicação possibilita o acesso à informação e amplia a capacidade de compreensão para atuação de forma plena na sociedade.

Nesse sentido, espera-se averiguar o nível do letramento em indivíduos com surdez, bem como as práticas de leitura e escrita utilizadas pelos docentes.

A partir da pesquisa, será possível refletir sobre o desenvolvimento de uma educação que eleve as potencialidades, as habilidades e competências das pessoas e da importância do letramento como um instrumento de formação cidadã.

\section{REFERÊNCIAS}

GUARINELLO, A. C.; MASSI, G.; BERBERIAN, A. P. Surdez e linguagem escrita: um estudo de caso. Revista Brasileira de educação especial, vol.13, n.2, pp.205-218, 2007, https://doi.org/10.1590/S1413$\underline{65382007000200005}$.

GUARINELLO, A. C. et al. Surdez e letramento: Pesquisa com surdos universitários de Curitiba e Florianópolis. Revista Brasileira de educação especial, Marília, v.15, n.1, p.99-120, jan./abr. 2009.

GUARINELLO, A. C. et. al. Clínica fonoaudiológica bilíngue, uma proposta terapêutica para surdos com a língua escrita: estudo de caso. CoDAS, São Paulo, vol.27, n.5, Sept./Oct. 2015.

LINS, H. A. M; NASCIMENTO, L.C.R. Algumas tendências e perspectivas em artigos publicados de 2009 a 2014 sobre surdez e educação de surdos. Pro-Posições, Campinas, vol.26, n.3, Sept./Dec. 2015.

MARIANI, B. Z. P. et al. O trabalho fonoaudiológico em uma clínica dialógica bilíngue: Estudo de caso. CoDAS, São Paulo, vol.28, n.5, Sept./Oct. 2016.

SCHEMBERG, S.; GUARINELLO, A. C.; SANTANA, A. P. O. As práticas de letramento na escola e na família no contexto da surdez: reflexões a partir do discurso dos pais e professores. Revista Brasileira de educação especial, vol.15, n.2, pp.251-268, 2009, https://doi.org/10.1590/S1413$\underline{65382009000200006 .}$.

SILVA, F. M. C. Práticas de letramento de alunos com surdez em srms1 no município de Marabá-Pa. Anais do I Simpósio de Linguística, Literatura e Ensino do Tocantins ISBN: 978-85-63526-36-6 11 a 13 de Novembro de 2013.

SILVA, G. M. O processo de ensino-aprendizagem da leitura em uma turma de alunos surdos: uma análise das interações mediadas pela Libras. Revista Brasileira de linguística aplicada, Belo Horizonte, vol.14, n.4, Oct./Dec. 2014.

WELTER, G.; VIDOR, D. C. G. M; CRUZ, C. R. Intervenções e Metodologias Empregadas no Ensino da Escrita e Leitura de Indivíduos Surdos: Revisão de Literatura. Revista Brasileira de educação especial, Marília, vol.21, n.3, July-Sept. 2015. 